\title{
From Scorecard to Social Learning: A Reflective Coassessment Approach for Promoting Multiagency Cooperation in Natural Resource Management
}

\author{
Dirk J.Roux $^{1,2}$, Kevin Murray ${ }^{3}$, Jeanne L. Nel $^{4}$, Liesl Hill ${ }^{4}$, Hermien Roux $^{5}$, and Amanda Driver ${ }^{6}$
}

\begin{abstract}
The responsibility for managing and conserving freshwater ecosystems is typically shared by multiple organizations with sometimes conflicting policy mandates. However, scorecard-based approaches for measuring management effectiveness in natural resource management are usually confined to single organizations. This paper describes a social learning approach which acknowledges cooperation as an essential precondition for effective management and that encourages reflective coassessment of cooperative relationships. The approach was pilot tested with eight participating organizations in one water management area in South Africa. It specifically aimed to allow for a multiagency reflective assessment of issues determining cooperative behavior, allow context-specific adaptations, and be embedded in adaptive management. It involved development of a spreadsheet-based scorecard-type tool that can be used to facilitate a multiagency workshop. This workshop serves to bring parties face-to-face and helps them codiscover their interdependence, shortcomings, and strengths. The spreadsheet structures reflection on their respective roles and effectiveness while the reflective coassessment motivates participants to address shortcomings. Overall, insights that emerged included: cooperation should be an explicit component of each organization's operational strategy; facilitation of appropriate cooperative behavior could be very effectively achieved by external "bridging organizations"; the reflective assessment process must be followed by purposefully adaptive interventions; the ability of the scorecard to be contextually adaptive was important; and institutional readiness requires investigation as the approach does sit somewhat uncomfortably with much current practice.
\end{abstract}

Key Words: adaptive management; bridging agents; cross-sector cooperation; freshwater conservation; integrated water resources management; management effectiveness evaluation; reflective coassessment; social learning

\section{INTRODUCTION}

Concerns regarding the effectiveness of natural resource conservation efforts have prompted the development of several systems to monitor and evaluate progress toward defined goals and to inform managers regarding where and how to improve (Stem et al. 2005, Hockings et al. 2006). Evaluation methods and approaches across the world differ considerably in their scale, depth, duration, and data collection methods (Ervin 2006, Leverington et al. 2008). The management effectiveness evaluation framework proposed by the International Union for the Conservation of Nature World Commission on Protected Areas
(IUCN-WCPA) has been the most influential in these developments (Hockings et al. 2006), providing a flexible overall framework to cater to these differing needs.

The IUCN-WCPA management effectiveness evaluation framework provides a consistent basis for designing evaluation systems for protected areas. The framework consists of six components, each comprising a number of evaluation indicators to assess management effectiveness. The six components are: context, to assess the cultural, biological, and political environment; planning, to assess design and planning; inputs, to assess adequacy of resources needed to manage; processes,

\footnotetext{
${ }^{1}$ Monash South Africa, ${ }^{2}$ International Water Centre, ${ }^{3}$ Insight Modelling Services, ${ }^{4}$ Council for Scientific and Industrial Research, ${ }^{5}$ North West Department of Agriculture, Conservation, Environment and Rural Development, ${ }^{6}$ South African National Biodiversity Institute
} 
to assess whether or not best possible management practices are used; outputs, to assess the implementation of management programs, actions, and services; and outcomes, to assess the extent to which objectives have been achieved (Hockings et al. 2006).

A distinct category of management effectiveness evaluations included in the IUCN-WCPA framework is the rapid scorecard assessments. The scorecard provides an instrument that aids in the undertaking of evaluation (Stem et al. 2005) and involves a structured questionnaire that is generally applied to each protected area through an interview, survey, or participatory workshop (Ervin 2006). The scorecard typically includes predefined assessment categories with a number of indicators per category and thresholds for each indicator. Scorecards can be relatively quick and easy to use and their clear, transparent, and simple presentation makes them a powerful communication tool (Stem et al. 2005). Examples include The Nature Conservancy Parks in Peril Site Consolidation Scorecard (TNC 2004), WWF Rapid Assessment and Prioritization of Protected Area Management (Ervin 2003), and World Bank/WWF Management Effectiveness Tracking Tool (Stolton et al. 2003).

Whereas scorecards have been developed to assess the management effectiveness of single organizations responsible for a particular protected area, the responsibility for managing freshwater ecosystems is typically shared by several organizations with overlapping and sometimes conflicting policy mandates (Roux et al. 2008). Rivers, for example, are impacted by activities that happen along their total lengths and throughout their entire catchments. Very few whole river catchments can be contained within protected areas. An integrated resource management approach is therefore required which considers the needs of both freshwater and terrestrial sectors inside and outside formally protected areas. Cooperation across sector and organization boundaries is therefore a fundamental stepping stone toward effective freshwater ecosystem management and conservation.

In this paper, cooperation is defined as agencies actively working together, i.e., moving in concert, for mutual benefit. No single agency has the power to command the behavior of the others and they retain their respective professional identities and cultural practices (Wondolleck and Yaffee 2000,
Kinnaman and Bleich 2004). Cooperation is not easy to achieve. It has costs, and benefits are not necessarily explicit and immediate. Although faceto-face interaction is often seen as time consuming, it can significantly promote the achievement of cooperation and the establishment of trusting relationships between individuals (Wondolleck and Yaffee 2000).

In the context of managing freshwater ecosystems, cooperative relationships have to cross boundaries defined not only by organizational affiliations, but also disciplinary backgrounds and vocabulary, sectoral policy contexts, social-ecological perceptions, and spatial and social jurisdictions. Based on these different contexts, each organization frames its responsibilities and acts on its mandate from a distinct "tradition of understanding" (Ison 2005). How do we establish trust and orchestrate effective action among groups who have such diverse realities and potentially different reference systems for interpreting information? Based on the contextspecific nature of cooperative management, a prepackaged strategy is unlikely to work. Many influential variables exist that can either enable or disable the associated social processes (Plummer 2009). As such, facilitation of cooperation requires a soft approach; one that encourages emergence of appropriate behavior rather than seeking a predefined outcome.

Social learning, or colearning, has emerged as a mechanism for facilitating shared understanding and collective action among diverse but interdependent parties (Blackmore 2007, Mostert et al. 2008, Van Bommel et al. 2009). It is a process of participative and iterative reflection through the sharing of experiences and ideas with others (Keen and Mahanty 2005), leading to cocreation of new understanding and adaptation (Pahl-Wostl and Hare 2004).

Social learning can be facilitated by a so-called bridging organization that is perceived to be neutral and is trusted by the relevant parties (Berkes 2009). Bridging organizations or agents can mobilize resources, utilize social incentives for ecosystem management, and provide interorganizational arenas for building trust, vertical and horizontal cooperation, learning, sense-making, identification of common interests, and conflict resolution (Hahn et al. 2006). The project team fulfilled the role of bridging agent in the pilot project reported on here. 
This paper presents a scorecard for reflective coassessment and associated approach that was developed with the initial intent of promoting effective management and conservation of freshwater ecosystems. However, our approach evolved from this initial focus to one with a stronger emphasis on facilitating social learning and establishing cooperative relationships as essential preconditions for effective freshwater management and conservation. The approach targets cooperation between agencies from different sectors with overlapping mandates for conserving freshwater ecosystems. It provides a tool for bridging agents to structure the process of promoting and improving cooperative behavior among coresponsible agencies. We document the development of the approach, discuss how it differs from conventional approaches, describe its application, and present a number of key lessons and recommendations.

\section{PILOT PROJECT: CONTEXT AND GEOGRAPHIC LOCATION}

Several South African rivers have been assessed for ecological condition (Strydom et al. 2006) and conservation status (Driver et al. 2005, Nel et al. 2007). This has highlighted the precarious condition of these systems; some $80 \%$ of ecosystems associated with large rivers can be considered threatened. To improve this undesirable situation, management responses can potentially benefit from existing and enabling policy frameworks for conserving freshwater ecosystems, including five cross-sector policy objectives developed for conserving South Africa's freshwater biodiversity. These objectives are to (1) set and entrench quantitative conservation targets for freshwater biodiversity, (2) plan for representation of freshwater biodiversity, (3) plan for persistence of freshwater biodiversity, (4) establish a portfolio of freshwater conservation areas, which may include, but are not restricted to, formal protected areas, and (5) enable effective implementation. The five objectives were further broken down into 20 implementation principles and approximately 50 cross-sector policy recommendations (Roux et al. 2006, Roux et al. 2008).

The original aim of this study was to develop a scorecard that could be used to measure progress toward the achievement of the cross-sector policy objectives for conserving South Africa's freshwater biodiversity. The need for achieving these conservation objectives through multiagency cooperation was a fundamental requirement. Our pilot study focused on fostering cooperation across sectors at the subnational level of government and specifically between line-function managers in organizations with a mandate to manage and conserve freshwater ecosystems.

Our study area, the Crocodile (West) and Marico Water Management Area (Croc-Marico WMA), is situated in the north-west of South Africa. It is one of 19 Water Management Areas delineated for the planning and management of water resources in South Africa (DWAF 2004). Its two main rivers are the Crocodile and the Marico rivers that flow northward to join the Limpopo River at their confluence. The Limpopo River occurs in an international river basin shared between Botswana, Mozambique, South Africa, and Zimbabwe, which ultimately flows into the Indian Ocean in Mozambique. In addition, the WMA straddles North West, Gauteng, and Limpopo provinces in South Africa.

Of the 19 WMAs of South Africa, the Croc-Marico WMA makes by far the biggest contribution to national GDP (approximately $25 \%$ ); it is the second most populous WMA (approximately 6.7 million people) and it generates the third lowest mean annual runoff. Large quantities of water are imported into the Crocodile River subcatchment from the river systems to the south to meet the current water demand. In this WMA, water is mainly used for urban, industrial, mining, and irrigation purposes and to a lesser degree for power generation and by rural communities (River Health Programme 2005).

A River Health survey conducted in 2004/2005 found that the rivers of the Croc-Marico WMA were generally in a "poor" condition with only isolated reaches still considered to be in a "natural" to "good" state (River Health Programme 2005). In a followup study, a systematic conservation plan was developed for the rivers of this WMA (Smith-Adao et al. 2006). A remaining challenge is that water resource management organizations embrace the results and implement the recommendations of studies such as these, and do so in concert.

Various government departments at the national level and from the three provinces have a mandate to manage and conserve the water resources of the Croc-Marico WMA. Cooperation within one 
province is challenging in itself. Cooperation across provincial boundaries is even more so. Some practical issues are inevitably encountered, e.g., monthly travel limits are imposed on officials and they may require special permission and lengthy motivations to travel outside provincial boundaries to attend meetings, partly for travel insurance reasons. High staff turnover rates also directly affect the ability to create interagency trust and working relationships and threaten continuity of initiatives. Limited numbers of ecologically skilled staff with associated over-commitment means it is often difficult to make time to cooperate effectively with counterparts from other organizations. Finally, departments or agencies sometimes know their budget allocations only halfway through the financial year, making it difficult to mobilize resources and to spend the budget by the end of a financial year or to commit to shared funding of initiatives.

Our pilot project included eight organizations, each with a mandated responsibility to manage and conserve freshwater ecosystems: three regional offices of the national department responsible for water affairs, three provincial environment affairs departments, a provincial parks board, and a group within the national biodiversity institute charged with wetland rehabilitation. A national Reference Group, under the guidance of the Water Research Commission (the main funder of the project), was also constituted to provide an ongoing review mechanism. This Reference Group consisted of experienced researchers and managers from national and provincial stakeholder agencies.

Over a period of two years, we developed and refined a reflective coassessment scorecard and step-wise assessment process for the Croc-Marico WMA, in close consultation with the Reference Group. Development of the scorecard and assessment process benefitted significantly from two pilot applications, one year apart, during which line-function staff from the implementation agencies provided a strong reality test. In addition, representatives from provincial and catchmentbased agencies from across South Africa were invited to participate in a stakeholder consultation meeting, hosted by the South African National Biodiversity Institute, to comment on the prototype scorecard and the general philosophy that was proposed for its use.

\section{REFLECTIVE COASSESSMENT TOOL}

\section{Scorecard}

Our first prototype scorecard was explicitly based on the six management components proposed by the IUCN-WCPA framework (Hockings et al. 2006). Indicators were chosen from this framework that were well aligned with the cross-sector policy objectives. Well-considered inputs from the pilot assessments and Reference Group reviews resulted in a number of significant adaptations to the scope and desired outcomes of the scorecard, as follows:

From a focus on effective management to a focus on cooperative behavior

Effective cooperation requires intangible inputs. For example, people need to spend time together developing relationships and learning to communicate with, and respect and trust, one another. It was decided that our scorecard should simply focus on facilitating the establishment of the professional and personal relationships that are required for improved cooperation. The latter was regarded as a necessary but often absent or neglected condition of the effective management of freshwater ecosystems. The scorecard was thus designed as a reflective assessment tool for promoting and sustaining long-term processes of social learning and cooperation.

From a single organization scorecard to a multiagency reflective and motivational assessment tool

At the onset of the project it was anticipated that the scorecard would enable a central agency, e.g., the South African National Biodiversity Institute, to monitor and audit the management effectiveness of provincial agencies. Motivated by our need to assess multiagency cooperation, we moved away from our initial intention to develop a performance scorecard for a particular organization to developing a reflective and motivational assessment tool for multiagency cooperative and adaptive behavior. Related issues that influenced the design of the scorecard were a desire to facilitate personal reflection and group learning; an interest in the spirit of cooperation more than in complying with the letter of the tool, i.e., to move away from punishment for not fulfilling an indicator, to reflection and discussion on why; and a wish to avoid mechanical ticking of boxes/filling in of scores and rather to get 
into complex social processes that may require more flexibility and ongoing involvement. Based on these considerations, we opted for a facilitated and interactive assessment process as opposed to mailing a questionnaire out for completion because much of the learning may happen through participating in the process of discussing the questions and compiling an evaluative report.

\section{From uniform application to context-specific adaptations}

Scorecards are commonly standardized to allow comparisons over time and among organizations. However, it was agreed that our assessment tool should allow flexibility to reflect varying contexts over time and among organizations as well as ongoing learning. The assessment tool should be dynamic in both structure, i.e., questions may change from year to year, and application, i.e., format may change over time and among agencies to reflect specific contexts and needs. We acknowledge that this preference for flexibility represents a trade-off that potentially imposes limitations on the ability of the scorecard to reveal trends over time. Flexibility may be appropriate while the scorecard is essentially in a testing phase while stronger emphasis on standardization may emerge once adoption of the scorecard becomes more widespread and its application more mature.

\section{From stand-alone application to being embedded in an adaptive management framework}

Adaptive management provides a sound management framework for dealing with uncertainties inherent to complex social-ecological systems and for integrating monitoring, learning, and management actions (Holling 2001). Essential to the practice of adaptive management is to have feedback loops in place that facilitate learning and adaptation over time (Biggs and Rogers 2003). Our scorecard indicators were formulated to promote reflection on key questions and to enable these feedbacks for adaptation. Representatives from one of the stakeholder agencies admitted that such reflection never happens in their work environment, let alone with partner agencies.

Following from the above adaptations, a second prototype was developed and piloted again with the subnational implementation agencies. Its purpose was to develop and refine the final reflective coassessment scorecard and assessment process presented here.
Our final scorecard was structured into four categories (Appendix A): context, where are we now?; planning, where do we want to be?; monitoring, what data are we collecting and how?; and management, how do we want to go about making a difference?. Within these categories, 26 key indicators were presented in specific questions with short descriptive criteria for a simple rating scale of 0 to 3 . The scorecard is available in hard copy format (Appendix A) and as an electronic spreadsheet (Appendix B). The electronic spreadsheet contains a number of worksheets and the instructions for using each worksheet are contained in the spreadsheet itself.

The statistics used to represent the collective were deliberately kept very simple to avoid having to embark on complicated explanations in the workshop on how to interpret the displayed results. Mean scores and the range of scores per indicator were the primary statistics. The range is a simple measure of the degree of similarity of scores for a given indicator. This is relevant because an issue of concern scored similarly for all organizations may require a different response from one scored very differently. Separate worksheets in the spreadsheet display overall results in a number of ways. The first shows the actual numbers, i.e., number of responses, minimum, mean, maximum, and range. The second highlights issues of concern (those indicators with low averages) and low similarity (a range of 2 or 3 ). The third worksheet displays two simple bar charts of the number of averages and number of similarity values in four categories (low, fair, good, high). The fourth worksheet displays a list of main issues of concern and the top 10 strengths. Each is also associated with a narrative description of the associated similarity. For example, one issue of concern might be "Use of existing statutes (the organizations scored this fairly differently)". Being captured in a spreadsheet also makes the scores, and indeed the comments, easily accessible for more sophisticated analyses that might be thought appropriate.

\section{Assessment process}

The assessment process described here is based on lessons derived from our use of the above scorecard during the two pilot assessments. These assessments took the form of multiagency workshops that were organized and facilitated by the project team at a venue within the study area. If necessary, the scorecard issues, indicators, or criteria as currently provided can be adapted to suit other contexts. 
If cooperative behavior or sufficient trust does not exist between participants then an independent broker or bridging agent should be considered to facilitate the process. Before the workshop, agency representatives are identified by considering the most appropriate organizations, i.e., those with a mandate for freshwater conservation or those whose cooperation is important for such mandates to be discharged, and the most appropriate representatives, e.g., people who are actively involved in the daily practice of managing freshwater ecosystems. Taking account of potential logistical and organizational difficulties, an appropriate day and venue is identified and invitations distributed.

The electronic spreadsheet (Appendix B) provides the main template for structuring the workshop proceedings and capturing the responses of the participants. At the start of the workshop, participants are given the opportunity to comment on and validate the scorecard indicators and criteria. If necessary, changes can be made before the scoring commences.

It must be stressed to participants that the quantitative scoring is only a means to an end; it is intended to encourage open and frank assessment and reflection by all participants on issues relating to cooperation within the context of freshwater ecosystem conservation in their area of joint jurisdiction. In addition to recording quantitative scores, the spreadsheet has a worksheet that allows comments to be recorded. However, for reasons of efficiency, it may be preferable to appoint a person other than the facilitator to record comments and observations in a copy of the spreadsheet. It is important to satisfy questions related to confidentiality of scores and comments, and to make very clear to participants what will happen to information gathered during the workshop.

Reflection is encouraged at a number of levels. Individual reflection is prompted directly by the criteria associated with each indicator. Intraorganizational coreflection is encouraged by requiring representatives from the same agency to reach consensus. Interorganizational coreflection is stimulated by the open and frank reflection of individuals across organizations. Finally, at the end of the workshop, the presentation of, for example, the overall distribution of scores and their similarity between organizations encourages a different and broader level of reflection prompted by the question: Does this overall result feel intuitively right? Similarly, lists of the main issues of concern as well as strengths, generated by the spreadsheet, prompt further discussion and reflection from yet another perspective. This kind of rethinking sometimes raised new issues or perspectives and can even result in earlier scores being reconsidered and indeed immediately changed if participants so wish.

There are various possible actions that can occur after the workshop, which would typically be executed by the facilitator or bridging agent. These include consolidation and summarizing comments and performing a detailed assessment. A more detailed assessment of the results as a whole, as opposed to the one performed by the spreadsheet facility on the day, may be considered appropriate. Alternatively, a summary of the workshop results can be produced. A decision on which assessment is most appropriate can be taken at the workshop. This would be driven particularly by the degree to which all participants feel that the workshop itself has provided an adequate basis for action to address the issues of concern. Should it be thought inadequate, then a more detailed analysis can be undertaken. This assessment would typically be recorded in a separate document and then circulated to participants for comment and input.

\section{DISCUSSION AND CONCLUSIONS}

The agencies in the study area agreed on the need for improved multiagency cooperation as a means to achieving effective river management and conservation. They experienced the assessment workshops as a useful step in this direction and were happy with external facilitation, with the project team essentially playing the role of bridging agent. Several agencies requested the project team to continue facilitation of the reflective process beyond the life of the project.

From the project team's perspective, the development of the scorecard and the application of it within the above process fulfilled our expectations to the extent that greater communication and interaction between the organizations was apparent. We developed the spreadsheet tool and assessment process ostensibly as an aid to get individuals from different agencies to meet face-to-face, in some instances for the first time; structure reflection on their respective roles and effectiveness in achieving conservation objectives for freshwater ecosystems; 
codiscover their mutual interdependence in regard to achieving freshwater conservation objectives; highlight current shortcomings and strengths related to cooperation; and be motivated to do something about shortcomings, at least through creating awareness of those shortcomings. Our approach places people and establishing trust between them first, believing such trusting relationships to be a precondition for cooperative and effective freshwater conservation to take place. We found this scorecard useful for structuring issues for reflection; however, it is the social process of periodic reflective assessment that is the essence of our approach.

We draw a number of key considerations and associated recommendations from our work. First, cooperation should be made an explicit organizational strategy. Cooperative management, or comanagement, among a broad array of actors has become a key area of attention in searching for more effective stewardship of natural resources (Plummer 2009). Our case study has focused on but one dimension of cooperation, namely horizontally across sectors at the same level of government, which we see as a critical enabling condition for achieving effective conservation of freshwater ecosystems. However, none of our participating agencies acted as if they have an explicit strategy for doing so. Such a cooperation strategy should reflect the degree to which continuity in both personal and interagency relations are valued. It should also make time and budget provisions to enable effective cooperation. We suggest that much work can be done to translate the rich literature on cooperation in natural resource management into practical strategies for agencies that are doing the day-to-day management.

Second, how can we facilitate appropriate cooperative behavior where this is lacking? Our experiences in this case study and other projects make us optimistic about the potential role of bridging agents to facilitate trust and relationship building and flows of knowledge across agency boundaries, including across science-implementation functions. Knowledge bridging is essentially mediated by face-to-face communication and social learning, which in turn have a positive effect on the development and maintenance of cooperation. Social learning, even if facilitated, is not always easy to achieve or successful in achieving its objectives (Van Bommel et al. 2009). Social learning and cooperation are complex processes and a bridging function requires skillful management of social patterns. Although appropriately experienced project teams can successfully play the role of bridging agents, the short-term nature of most research projects is problematic. To effectively fulfill the role of a bridging agent requires more time than we initially planned for and would typically need to extend beyond the time frames of a two- to three-year project. By implication, a new funding model is required to enable bridging agents. This promising but relatively new concept requires further exploration, for example to better understand the roles and responsibilities of bridging agents, factors influencing their legitimacy, their funding models, and how external or internal bridging agents compare.

Third, a logical step to follow after a reflective assessment is the advancement of purposefully adaptive interventions. In essence, reflection must be linked to action. Agencies generally acknowledge that they have to practice adaptive management, but are mostly at a loss as how to do so. This reflective coassessment scorecard provides a tangible mechanism for promoting reflection in line with the goals of adaptive management. Identified actions may differ between organizations and some issues may require action by only one organization while other issues may require joint or cooperative action.

Our fourth point relates to a novelty of our approach in that it explicitly allows for context specific adaptations over time and across applications. This begs the question to what degree the scorecard can be modified and applied to other areas of work where improved cooperation is an essential condition or at least an important consideration. Examples may include public-private sector cooperation in environmental matters and even interdepartmental cooperation within the same agency. Further investigation in different settings is required.

Our fifth and final lesson relates to institutional readiness for an approach such as this. In the drive to promote the use of new knowledge in the management of natural resources, funding agencies, researchers, and users of research have become relatively familiar with the concepts of information transfer, consulting, and public participation. Social learning, as a relatively recent entrant in the 'sustainability toolbox', represents a significant expansion of these paradigms (Allan and Wilson 
2009). As opposed to a tangible product, such as a report that can be transferred, it is concerned with intangible variables that stimulate the development of a common purpose and relationships, believing that norms of reciprocity and a general culture of cooperation will emerge. For us, a key outcome would be to achieve a mind-set where 'coreflection' is viewed as a critical requirement to adaptive management and effective conservation of freshwater ecosystems. This lack of a tangible deliverable at a fixed deadline sits uncomfortably with current practice, and research is required into an institutional environment that will enable social learning as a legitimate intervention. For the interim, we believe that some emphasis should therefore be placed on the production of a workshop report, which would present the results contained in the scorecard spreadsheet tool and can form the basis of postworkshop actions. Such a tangible product in no way invalidates the real reflection and learning that has taken place.

With its focus on stimulating cooperation, reflective coassessment represents a new approach to promoting effective conservation of freshwater ecosystems. Social learning is seen as the enabling process that facilitates discovery of common purpose, cocreation, and legitimization of relevant knowledge and adaptive action by agencies based on reciprocal relationships. This new approach requires a dedicated research program to test its usefulness against early assumptions and to this end we make the electronic scorecard available with the hope that other workers will modify and apply it to various contextual settings.

Responses to this article can be read online at: http://www.ecologyandsociety.org/voll6/issl/art24/ responses/

\section{Acknowledgments:}

This project was supported by the Water Research Commission (project K5/1710), WWF-SA and the CSIR. We are grateful to the several practitioners from various national and provincial agencies who gave their time and comments during the course of the project. In particular, we would like to acknowledge the considerable guidance received from Charles Breen, Harry Biggs, Kevin Rogers, and Steve Mitchell. The thoughtful suggestions of three anonymous reviewers significantly assisted us in preparing the final version of the manuscript.

\section{LITERATURE CITED}

Allan, C., and B. P. Wilson. 2009. Meeting in the middle: desirable but not easy. Environmental Policy and Governance 19:38-399.

Berkes, F. 2009. Evolution of co-management: role of knowledge generation, bridging organizations and social learning. Journal of Environmental Management 90:1692-1702.

Biggs, H. C., and K. H. Rogers. 2003. An adaptive system to link science, monitoring and management in practice. Pages 59-80 in J. T. du Toit, K. H. Rogers, and H. C. Biggs, editors. The Kruger experience: ecology and management of savanna heterogeneity. Island Press, Washington, D.C., USA.

Blackmore, C. 2007. What kinds of knowledge, knowing and learning are required for addressing resource dilemmas? A theoretical overview. Environmental Science and Policy 10:512-525.

Driver, A., K. Maze, M. Rouget, A. T. Lombard, J. L. Nel, J. K. Turpie, R. M. Cowling, P. Desmet, P. Goodman, J. Harris, Z. Jonas, B. Reyers, K. Sink, and T. Strauss. 2005. National spatial biodiversity assessment 2004: priorities for biodiversity conservation in South Africa. Strelitzia 17:1-45.

Department of Water Affairs and Forestry (DWAF). 2004. National water resources strategy. Department of Water Affairs and Forestry, Pretoria, South Africa.

Ervin, J. 2003. Rapid Assessment and Prioritization of Protected Area Management (RAPPAM) methodology. WWF, Gland, Switzerland.

Ervin, J. 2006. Assessing protected area management effectiveness: a quick guide. The Nature Conservancy, Arlington, Virginia, USA.

Hahn, T., P. Olsson, C. Folke, and K. Johansson. 2006. Trust-building, knowledge generation and organizational innovations: the role of a bridging organization for adaptive comanagement of a 
wetland landscape around Kristianstad, Sweden. Human Ecology 34:573-592.

Hockings, M., S. Stolton, F. Leverington, N. Dudley, and J. Courrau. 2006. Evaluating effectiveness: a framework for assessing management effectiveness of protected areas. Second edition. International Union for the Conservation of Nature, Gland, Switzerland.

Holling, C. S. 2001. Understanding the complexity of economic, ecological and social systems. Ecosystems 4:390-405.

Ison, R. 2005. Traditions of understanding: language, dialogue and experience. Pages 22-40 in M. Keen, V. A. Brown, and R. Dyball, editors. Social learning in environmental management. Earthscan, London, UK.

Keen, M., and S. Mahanty. 2005. Collaborative learning: bridging scales and interests. Pages 104-120 in M. Keen, V. A. Brown, and R. Dyball, editors. Social learning in environmental management. Earthscan, London, UK.

Kinnaman, M. L., and M. R. Bleich. 2004. Collaboration: aligning to create and sustain partnerships. Journal of Professional Nursing 20:310-322.

Leverington, F., M. Hockings, H. Pavese, K. L. Costa, and J. Courrau. 2008. Management effectiveness evaluation in protected areas - a global study: overview of approaches and methodologies. World Wildlife Fund, The Nature Conservancy, International Union for the Conservation of Nature World Conservation Monitoring Centre, University of Queensland, Gatton, Australia.

Mostert, E., M. Craps, and C. Pahl-Wostl. 2008. Social learning: the key to integrated water resources management? Water International 33 (3):293-304.

Nel, J. L., D. J. Roux, G. Maree, C. J. Kleynhans, J. Moolman, B. Reyers, M. Rouget, and R. M. Cowling. 2007. Rivers in peril inside and outside protected areas: a systematic approach to conservation assessment of river ecosystems. Diversity and Distributions 13:341-352.

Pahl-Wostl, C., and M. Hare. 2004. Processes of social learning in integrated resources management.
Journal of Community and Applied Social Psychology 14:193-206.

Plummer, R. 2009. The adaptive co-management process: an initial synthesis of representative models and influential variables. Ecology and Society 14(2): 24. [online] URL: http://www.ecolog yandsociety.org/vol14/iss2/art24/.

River Health Programme. 2005. State-of-rivers report: monitoring and managing the ecological state of rivers in the Crocodile (West) Marico Water Management Area. Department of Environmental Affairs and Tourism, Pretoria, South Africa.

Roux, D. J., P. J. Ashton, J. L. Nel, and H. M. MacKay. 2008. Improving cross-sector policy integration and cooperation in support of freshwater conservation. Conservation Biology 22:1382-1387.

Roux, D. J., J. L. Nel, H. M. MacKay, and P. J. Ashton. 2006. Cross-sector policy objectives for conserving South Africa's inland water biodiversity. Report TT 276/06. Water Research Commission, Pretoria, South Africa. [online] URL: http://www.w aternet.co.za/rivercons/docs/full roux cross secto r policy objectives.pdf.

Smith-Adao, L. B., J. L. Nel, D. J. Roux, L. Schonegevel, D. Hardwick, G. Maree, L. Hill, H. Roux, C. J. Kleynhans, J. Moolman, C. Thirion, and C. Todd. 2006. A systematic conservation plan for the freshwater biodiversity of the Crocodile (West) and Marico Water Management Area. Contract report produced for the Department of Water Affairs and Forestry. CSIR Report No CSIR/NRE/ ECO/2006/0133/C. CSIR Natural Resources and the Environment, Pretoria, South Africa. [online] URL: http://www.waternet.co.za/rivercons/docs/ full smith-adao crocodile-west marico wma.pdf

Stem, C., R. Margoluis, N. Salafsky, and M. Brown. 2005. Monitoring and evaluation in conservation: a review of trends and approaches. Conservation Biology 19(2):295-309.

Stolton, S., M. Hockings, N. Dudley, K. MacKinnon, and T. Whitten. 2003. Reporting progress in protected areas: a site-level management effectiveness tracking tool. World Bank/WWF Alliance for Forest Conservation and Sustainable Use, Washington, D.C., USA. 
Strydom, W. F., L. Hill, and E. Elof, editors. 2006. Achievements of the River Health Programme 1994-2004: a national perspective on the ecological health of selected South African rivers. Department of Water Affairs and Forestry, Pretoria, South Africa.

The Nature Conservancy (TNC). 2004. Measuring success: the parks in peril site consolidation scorecard manual. The Nature Conservancy, Arlington, Virginia, USA.

Van Bommel, S., N. Röling, N. Aarts, and E. Turnhout. 2009. Social learning for solving complex problems: a promising solution or wishful thinking? A case study of multi-actor negotiations for the integrated management and sustainable use of the Drentsche Aa area in the Netherlands. Environmental Policy and Governance 19:400-412.

Wondolleck, J. M., and S. L. Yaffee. 2000. Making collaboration work. Island Press, Washington, D. C., USA. 


\section{APPENDIX A. The Issues, Indicators and Criteria of the Reflective Co-assessment Scorecard}

1

CONTEXT Issue 1 : Clarity of respective mandates

Do you have a clear understanding of the mandate of your and relevant other organisations in relation to management of freshwater ecosystems?

Do not have a clear understanding of my organisation's mandate

Understand my organisation's mandate

Understand my organisation's mandate and have some understanding of the mandates of partner organisations Have a clear understanding of the complementarity between the mandates of my organisation and those of partner organisations

CONTEXT Issue 2 : Current culture of cooperation

What is the current culture of cooperation between you and your partner organisation/s regarding freshwater ecosystem monitoring and management?

Virtually no co-operation takes place between you and your partner organisation/s

There is informal co-operation between you and your partner organisation/s on an irregular basis

There is regular but not formalised co-operation between you and your partner organisation/s

There is regular AND formalised co-operation between you and your partner organisation/s regarding the conservation of freshwater ecosystems

3

CONTEXT Issue 3 : Appropriate statutes

\begin{tabular}{|l|}
\hline 0 \\
\hline 1 \\
\hline 2 \\
3 \\
\hline
\end{tabular}

\section{Are legal mechanisms in place for the conservation of freshwater ecosystems?}

There are no legal mechanisms for the conservation of freshwater ecosystems

Relevant parties are in agreement on the need for legal mechanisms for the conservation of freshwater ecosystems but the process of drawing up legal mechanisms has begun but is still incomplete

Sufficient legal mechanisms for the conservation of freshwater ecosystems are in place

Sufficient legal mechanisms for the conservation of freshwater ecosystems are in place and priority freshwater ecosystems are explicitly and effectively linked to these mechanisms

\begin{tabular}{|l|}
\hline 0 \\
\hline 1 \\
\hline 2 \\
\hline 3 \\
\hline
\end{tabular}

\begin{tabular}{|l|}
\hline 0 \\
\hline 1 \\
\hline 2 \\
\hline 3 \\
\hline
\end{tabular}


In relation to how freshwater ecosystems may be affected, are agricultural, mining and industrial uses of land and water being regulated? No mechanisms exist for regulating agricultural, mining and industrial uses of land and water 0

Mechanisms for regulating agricultural, mining and industrial uses of land and water exist but there are major problems in implementing them 1 effectively

Mechanisms for regulating agricultural, mining and industrial uses of land and water exist with few problems in implementing them effectively

Mechanisms for regulating agricultural and industrial uses of land and water exist and are implemented effectively

5

Is there sufficient capacity in your organisations to implement agricultural, mining and industrial water and land use regulations effectively?

There is no effective capacity/resources to implement agricultural, mining and industrial water and land use regulations effectively

There are major deficiencies in staff capacity/resources to implement agricultural, mining and industrial water and land use regulations effectively (for example, high staff turnover and insufficient budget)

There is reasonable capacity to implement agricultural, mining and industrial water and land use regulations effectively, but some deficiencies remain

There is excellent capacity/resources to implement agricultural, mining and industrial water and land use regulations effectively

6 CONTEXT Issue 6 : Staff numbers

Do you have sufficient staff and all the required skills (in your organisation) to effectively conserve freshwater ecosystems? Consider whether you have the following skills or capacity: Fish biologist; aquatic invertebrate specialist; water quality specialist; hydrologist; botanist; geomorphologist; wetland ecologist; GIS specialist; conservation planner

There are no such staff

Such staff numbers are inadequate and staff are unqualified Such staff numbers are below optimum level, but staff are well qualified

Such staff numbers are adequate and staff are qualified to undertake freshwater ecosystem conservation planning 7

CONTEXT Issue 7 : Staff training

Do staff in your organisation receive appropriate training in freshwater ecosystem conservation?

\author{
Staff undergo no training \\ Staff receive generic training only
}

Staff receive only theoretical (e.g. conferences or courses) or practical training (e.g. fieldwork and application of methodologies) in freshwater ecosystem conservation

\begin{tabular}{|l|}
\hline 0 \\
\hline 1 \\
\hline 2 \\
\hline
\end{tabular}


Do you have sufficient equipment in your organisation to effectively conserve freshwater ecosystems?

There is limited or no equipment and facilities

There is some equipment and facilities, but these are wholly inadequate

There is equipment and facilities, but still some major gaps that constrain management

There is adequate equipment and facilities

9

CONTEXT Issue 9 : Ability to influence budget

Do you know your available budget for freshwater ecosystems conservation and can you influence it?

The size of the budget is not made known and it is impossible to influence it

The size of the budget is only made known after the start of the financial year and cannot be influenced

The size of the budget is made known at the beginning of the financial year and can be influenced to a certain extent

The size of the budget is known at least one year in advance and can be influenced prior to allocation

10 CONTEXT Issue 10 : Adequacy of budget

\section{Is your internal budget adequate for the implementation of your freshwater objectives?}

There is no secure internal budget for freshwater ecosystem conservation and management for your organisation, which is wholly reliant on external funding

There is very little secure internal funding, and your organisation cannot implement freshwater objectives without external funding

There is a reasonably secure core internal budget

There is a secure internal budget for freshwater ecosystem conservation planning and implementation on a multi-year cycle

11

CONTEXT Issue 11 : Social learning

Are you learning about freshwater ecosystems management with your partners? (inter-organisation)

No social learning takes place between partners

Limited and mostly ad hoc social learning takes place, either in the field or during meetings

Planned events take place occasionally during which social learning includes both theory and practice

Regular and planned events take place during which social learning includes both theory (e.g. conceptual discussions) and practice (e.g. fieldwork) 
Do you have a champion to coordinate inter-organisational cooperation for freshwater ecosystem conservation (individual or core group)?

No individual or core group has emerged as a champion for partner cooperation

Partners meet on an ad hoc basis and without the direction of a champion

A champion coordinates some relevant activities on an annual basis

A champion is accepted by all partners and he/she actively facilitates coordinated action and co-learning and this role is supported by your

13

CONTEXT Issue 13 : Networking support

organisation

\section{Does your organisation provide support for networking with partners? (intra-organisation)}

Your organisation provides no support for external networking

Your organisation provides limited support for networking with immediate partner organisations

Your organisation provides logistical, technological and financial support for networking with partner organisations

Your organisation actively promotes and provides logistical, technological and financial support for networking with partner organisations as well as with external, but relevant knowledge sources (e.g. universities, conferences)

\section{CONTEXT Issue 14 : Trust}

Is there a healthy level of trust between partners? (inter-organisation)

You do not know who your counterparts are or have virtually no contact with them

Limited and ad hoc interaction between counterparts takes place and there is no working relationship

You feel comfortable to ask your counterpart(s) for assistance in achieving your mandate

It comes naturally to phone your counterparts and freely discuss issues related to freshwater ecosystem conservation, including mutual problem solving across organisational boundaries

15

CONTEXT Issue 15 : Perceived value of freshwater ecosystems

\section{Are freshwater ecosystems valued?}

The need to conserve freshwater ecosystems is rather invisible or obscure within the portfolio of organisational priorities

Your organisation shows significant intent to conserve freshwater ecosystems, but lacks in implementation

The need to conserve freshwater ecosystems is widely understood in your organisation and some success stories exist

Conservation of freshwater ecosystems features as a high priority on management and policy agendas and this is reflected in strong support

for initiatives to understand, identify and conserve freshwater ecosystems 
Is there a social mechanism for sharing between your organisations the allocation of complementary management targets, keeping in mind land use planning, high value conservation areas, connecting gradients, recognition of natural disturbances?

No targets have been set Conservation targets have been set but we were not involved

We were involved in target setting but lack inclusive ownership

Target setting is an ongoing and fully participatory process, including involvement from organisations outside our domain of responsibility to ensure that large-scale ecosystem processes are covered

17 PLANNING Issue 17 : Integration of spatial plans

Are different forms of spatial planning in your region well aligned? (inter-organisation)

Each form of spatial planning takes place in isolation Some sharing of data and products takes place between planning initiatives

Sharing is common and some integration takes place

Full integration takes place between spatial planning, including freshwater and terrestrial conservation planning, catchment management planning and spatial development planning

18 PLANNING Issue 18 : Integration between conservation plan and strategic/work plans

Are these priorities reflected in your organisation's strategic plan / work plan?

Conservation priorities and actions are not reflected in the strategic plan of the organisation and work plans of individuals

Priorities are reflected in the strategic and work plans but are only partially implemented

Priorities are fully integrated in strategic and work plans and implemented Priorities are fully integrated in strategic and work plans, implemented and are regularly reviewed MONITORING Issue 19 : Resource inventory

Does your organisation (department) have enough information to manage the area?

There is little or no information available on the critical habitats, species and cultural values of the area (province or management area) Information on the critical habitats, species and cultural values of the area (province or management area) is insufficient to support planning and decision making

Information on the critical habitats, species and cultural values of the area (province or management area) is not quite sufficient to support planning and decision making but new initiatives to collect information are in place

Information on the critical habitats, species and cultural values of the area (province or management area) is sufficient to support planning and decision making and necessary survey work is being maintained

\begin{tabular}{|l|}
\hline 0 \\
\hline 1 \\
\hline 2 \\
\hline 3 \\
\hline
\end{tabular}


Is monitoring aligned with the achievement of freshwater ecosystem conservation objectives? (intra-organisation)

No relevant monitoring is undertaken by your organisation

Some relevant monitoring is undertaken

Your organisation actively participates in a relevant monitoring programme, e.g. the River Health Programme, but does not link results directly to conservation objectives

A monitoring programme that is aligned with freshwater ecosystem conservation objectives and targets (e.g. the River Health Programme) has official status and is being maintained

21 MONITORING Issue 21 : Cooperation in monitoring

Are monitoring responsibilities shared amongst partners? (inter-organisation)

Different monitoring activities take place in isolation; not familiar with partners' monitoring activities

Aware of partners' monitoring activities, but no cooperation is taking place

Some cooperation in monitoring, but information management systems remain independent

There is integrated design (agreed-on indicators) and coordination in monitoring amongst all partners; compatibility of, access to, and transfer

22

MANAGEMENT Issue 22 : Monitoring-reporting-management integration

Do you have an integrated monitoring, reporting and management system? (intra-organisation)

of data is well advanced

No monitoring or reporting takes place

Monitoring or reporting takes place but not as a linked system

Regular monitoring and reporting take place and are mutually reinforcing

Regular monitoring and reporting activities take place, are mutually reinforcing, linked to conservation targets, and a clear mechanism exists for results to inform management decisions (adaptive management)

23

MANAGEMENT Issue 23 : Management plans

Are there management plans for freshwater ecosystem conservation areas (that may include wetlands, rivers, estuaries, etc.)?

There are no management plans for freshwater ecosystem conservation areas

Some management plans exist or are being developed

Management plans exist for the majority of identified freshwater ecosystem conservation areas

Each identified freshwater ecosystem conservation area has a management plan that includes required actions, target objectives, timeframes and responsibilities 
Is there a science-management link/continuum in place (where some scientists act as managers and some managers act as scientists?)

We do not have any scientists

Scientists and managers work completely separately

Scientists and managers work together to some extent

25

Scientists and managers actively and constructively influence each other's thinking and actions MANAGEMENT Issue 25 : Impact of conservation plan on decision making

Are land-use decisions and water use allocations in the area made in accordance with specific guidelines based on your conservation plan?

Decisions are not made according to any set process or guidelines

Guidelines exist but there is a lack of clarity on whether decisions are made in accordance with them

Guidelines exist and the compliance of decisions to the guidelines are monitored, but a significant number of decisions are not made in accordance with the guidelines

Guidelines exist and the compliance of decisions is monitored and the majority of the decisions are in compliance with the guidelines MANAGEMENT Issue 26 : Reporting

Are regular reports produced on the status of freshwater ecosystems?

No reports are produced

Reports are produced irregularly and not based on quantitative data

Reports are produced regularly and are based on quantitative data, but do not show trends over time or relate directly to decision-making or objectives

Reports are produced regularly based on consistent indicators which track changes over time and feed directly into decision-making

\begin{tabular}{|l|}
\hline 0 \\
\hline 1 \\
\hline 2 \\
\hline 3 \\
\hline
\end{tabular}

\begin{tabular}{|l|}
\hline 0 \\
\hline 1 \\
\hline 2 \\
\hline 3 \\
\hline
\end{tabular}

\section{3}

\begin{tabular}{|l|}
\hline 0 \\
\hline 1 \\
\hline 2 \\
\hline 3 \\
\hline
\end{tabular}


Appendix 2. Scorecard spreadsheet to facilitate reflective co-assessment for promoting multi-agency cooperation in natural resource management (Microsoft Office Excel file).

Please click here to download file 'appendix2.xls'. 